\title{
Free Fibular Flap in Mandibular Defect Reconstruction in Perspective of a Tertiary Care Hospital of Bangladesh
}

\author{
Mohammad Iqbal Kabir *1, Muhammad Mizanur Rahaman ${ }^{2}$, Md. Atiqul Islam Rabby ${ }^{3}$, \\ Shamim Hasan ${ }^{4}$, Md. Abdur Rob ${ }^{5}$, Golam Mohiuddin Chowdhury ${ }^{6}$, Ismat Ara Haider ${ }^{7}$
}

\section{Abstract}

Introduction: The principal objectives of reconstruction after mandible resection are to restore physiological articulation, chewing, swallowing functions and esthetics of the patient. Metal plate and bone graft are usually used to achieve this purpose.From the point of view of bone resorption and augmented exposure to infection, free vascularized fibular flap $(F F F)$, comprising alive bone, have shown a lower infection rate and high rate of success. Materials and Methods: The study population of this clinical report included undertaking mandibular reconstruction by transplantation of a free vascularized fibular flap at the Department of Oral and Maxillofacial Surgery at the Dhaka Dental College between May 2014 to November 2014. The factors consider for studying were as following-age, sex, primary disease , period of reconstruction, mandibular defect classification, mandible resection range, height of reconstructed mandibular bone, number of locations of mandible osteotomy, vascular anastomosis and complication. Results: Primary disease comprised one was ameloblastoma, one was recurrent ameloblastoma, and another was post-surgical facial deformity. According to the CAT classification body was the most commonly observed defect. All mandibular bones were left as single barrel. There were 2 cases of primary reconstruction and 1 of secondary reconstruction. Free fibular flap ranges from $12-18 \mathrm{~cm}$. No postoperative complications were seen in any case. Conclusion: Vascularized fibular flap is good choice in wide-range faults hard to fill with an iliac block graft. Further studies including greater samples of patients undertaking fibular bone transplantation are needed to comparatively investigate its merits in more detail.

Keywords: Mandibular defects, Reconstruction, Free Fibular Flap (FFF), Bangladesh.

Number of Table: 01; Number of Figures: 04; Number of References: 23; Number of Correspondence: 07

*1. Corresponding Author:

Lt. Col Dr. Mohammad Iqbal Kabir

BDS, D-OMS, MCPS, FCPS

Chittagong Combined Military Hospital

Chittagong, Bangladesh.

E-mail: iqbalkabir61@gmail.com

Mobile: +8801712212145

2. Dr. Muhammad Mizanur Rahaman, BDS, FCPS

Associate Professor \& Head

Department of Oral \& Maxillofacial Surgery

Mandy Dental College, Dhaka, Bangladesh.

3. Dr. Md. Atiqul Islam Rabby, BDS

Lecturer

Marks Medical College (Dental Unit)

Dhaka, Bangladesh.

4. Dr. Shamim Hasan, FCPS, MS

Plastic Surgeon

Dhaka Medical College \& Hospital, Dhaka.

5. Brig. Gen Dr. Md. Abdur Rob

Commandant \& Head

Oral \& Maxillofacial Surgery

Military Dental Centre, Jessor.

6. Major Gen Dr. Golam Mohiuddin Chowdhury

Consultant Dental Surgeon General

Directorate General of Medical Services

Bangladesh Army.

7. Professor Dr. Ismat Ara Haider

Professor \& Head

Oral \& Maxillofacial Surgery

Dhaka Dental College, Dhaka.

\section{Introduction}

After mandible resection impairment of functions are seen including articulation, chewing, swallowing, and esthetics. The Principal objectives of reconstruction are to restore the functions. Metal plate and bone graft are usually used to achieve this purpose. At present, a free vascularized fibular flap is the most frequently used biomaterial for this purpose. Iliac horn bone is similar to that of the mandible in ration of cortex and cancellous. Suchlike grafts are deliberated to be the most appropriate for mandibular reconstruction ${ }^{1}$. From the point of view of bone resorption and augmented exposure to infection, free vascularized fibular flap(FFF), comprising alive bone, have shown a lower infection rate and high rate of success ${ }^{2}$. That's why now a day's free vascularized fibular flap is standard use in mandibular reconstruction ${ }^{3,4,5}$.

The application of FFF in transplantation was first reported in 1975 by G IAN Taylor in Melbourne, Australia ${ }^{6}$. And their pioneer practice in the craniocervical region was reported in 1989 by David A Hidalgo ${ }^{7}$.Peroneal artery and vein were trusted as the main feeding vessel $^{4}$. It is possible to reap flap of greater than $20 \mathrm{~cm}$ in length creating it as a convenient apparatus in the reconstruction of wide range of mandibular bone defect ${ }^{4}$.

Osteotomies can to be performed at multiple locations and also can reap with the patient in the supine position. Postoperative complications which are associated to the site of harvest are very little. According to PubMed and Google Scholar no study has been conducted in Bangladesh regarding reconstruction of mandibular defects with free fibular flap (FFF). This delineation designates mandibular reconstruction using vascularized fibular flap at the Oral 
and Maxillofacial surgery department of Dhaka Dental College, Bangladesh. In designing of manuscript we follow the pattern of clinical report of The Bulletin of Tokyo Dental College by Yamamoto $\mathrm{N}$ et.al.

\section{Materials and Methods}

\section{Patient}

The study population of this clinical report included undertaking mandibular reconstruction by transplantation of a free vascularized fibular flap. All had undertaken segmental resection of the mandible at the Department of Oral and Maxillofacial Surgery at the Dhaka Dental College \& Hospital over a period of 06 months, between May 2014 and November 2014.

\section{Essential factors consideration in cases}

The factors consider for studying were as following- age, sex, primary disease, period of reconstruction, mandibular defect classification, mandible resection range, height of reconstructed mandibular bone, number of locations of mandible osteotomy, vascular anastomosis and complication. Nobuharu Yamamoto considered the following factors in his study ${ }^{4}$. According to CAT system of Hashikawa Mandibular defect classification was carried out (Condylar Head, Mandibular Angle, mental Tubercle) ${ }^{8}$.

The inclusion and exclusion criteria for fibular transplantation

Patients with systemic illness in whom it would have been problematic to execute surgery under general anesthesia, and those supposed of having deep vein thrombosis were excluded from the study. Informedwritten consent was taken from all patients for inclusion in this study.

Infection or necrosis of bone transplanted at the time of primary reconstruction; multiple failure of the metal plate for reconstruction; an extensive defect range in the mandible, making reconstruction by transplantation of an iliac bone block graft potentially difficult; and radiation osteomyelitis.

As per fibular flap is alive bone with blood flow, it has tough resistance to infection, creating it the most appropriate type of flap for a wide range of defects. Considering of these benefit, fibular bone grafts are nominated at our department as the primary treatment in cases of mandibular reconstruction.

\section{CAT classification}

According to Yamamoto $\mathrm{N}$ et al. three factors are used to determine the CAT classification. Creating total of 6 bilaterally customary points: the Condylar Head, Mandibular Angle, and Mental Tubercle. The mandibular defect is classified by a combination of these points. If a defect contains a typical point, it is classified as $\mathrm{C}, \mathrm{A}$, or $\mathrm{T}$; if it contains multiple usual point, it is classified as CA, AT, or CAT. If a case includes resection at standard points, it is not included in the classification. If a fault is limited to the mandibular ramus with no typical point, it is classified as Neck; if it is restricted to the body of the mandible, it is classified as Body. According to Yamamoto $\mathrm{N}$ et al. the CAT classification may be summarized as follows:1) there are 14 classification patterns; 2) only bone defects are included (soft tissue defects are not addressed); and 3) classification is simple to perform (fig 1 ).

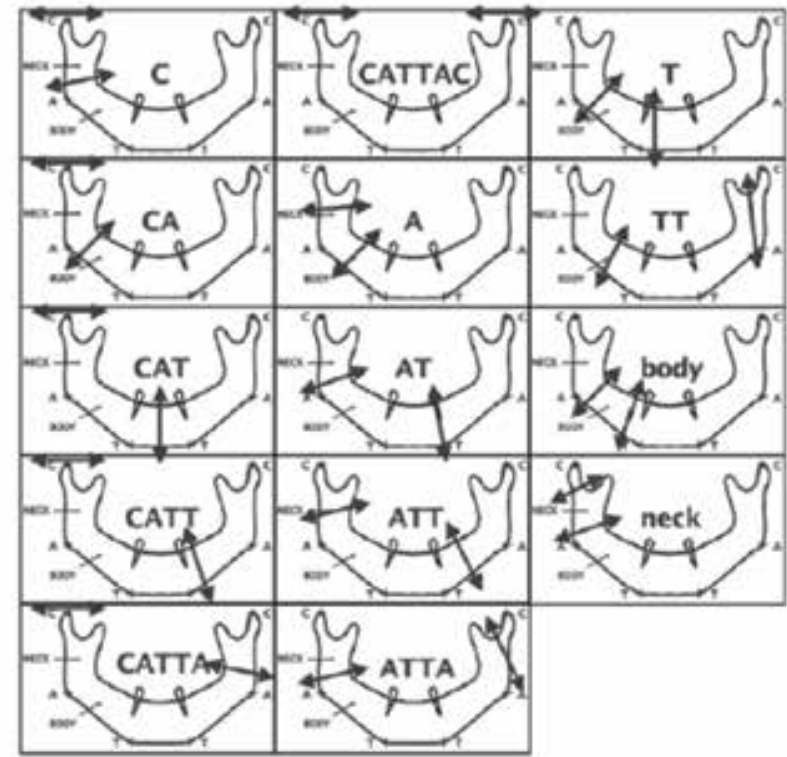

Figure-1: CAT classification (Condylar Head, Mandibular Angle, and Mental Tubercle).

\section{Method}

The principal disease, mandible resection range, and number of mandible osteotomy sites, presence or absence of postoperative complications were considered. A skin flap was also reaped during engraftment of the bone flap and assessed as an observing factor.

Mandibular defects including standard point were described as $\mathrm{C}, \mathrm{A}$, or $\mathrm{T}$; defects with multiple standard points were classified as $\mathrm{CA}, \mathrm{AT}$, or CAT. If resection was performed at standard point, it was not classified as defect. Defect of mandibular ramus only was classified as Neck, while that for the body of the mandible only was classified as Body. Classification patterns are listed as C, A, T, CA, AT, ATT, CATT, ATTA, CATTA, CATTAC, Neck or Body. The vascular anastomotic was set as in case of artery, the peroneal artery with facial artery; and in case of vein, the peroneal Vain with jugular or lingual or facial vein. Prolene (8-0) was used to ligature in all vascular anastomosis cases. All segment osteotomies were shaped with reconstruction plate.

\section{Results}

Two of the patients were men, and one was women. Age ranged from 25-26 years. Primary disease comprised one was ameloblastoma, one was recurrent ameloblastoma, and another was post-surgical facial deformity. According to the CAT classification, Body was the most commonly observed defect. The resection range of the mandible was 11-20 (mean $15.5 \mathrm{~cm}$ ). All mandibular bones were left as single barrel. There were 2 cases of primary reconstruction 
and 1 of secondary reconstruction. Subtotal mandibulectomy was done in all cases. Free fibular flap ranges from 12-18 cm; segmented osteotomy ranges from 3-5 segments. No postoperative complications were seen in any case. Patient's information summary has been shown in table I.

Table-I: Patients information summary.

\begin{tabular}{|c|c|c|c|c|c|c|c|c|c|}
\hline 品 & 夡 & 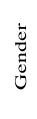 & Primary Disease & $\begin{array}{l}\text { Reconstruct } \\
\text { ion }\end{array}$ & $\begin{array}{l}\text { Mandibular } \\
\text { resection } \\
\text { range }\end{array}$ & $\begin{array}{l}\text { Mandibulectomy } \\
\text { type }\end{array}$ & $\begin{array}{l}\text { Fibular } \\
\text { flap } \\
\text { range }\end{array}$ & $\begin{array}{l}\text { Segmented } \\
\text { osteotomy }\end{array}$ & 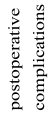 \\
\hline 1 & 26 & $\mathrm{M}$ & Ameloblastoma & Primary & $12 \mathrm{~cm}$ & Subtotal & $12 \mathrm{~cm}$ & 3 segment & No \\
\hline 2 & 25 & M & $\begin{array}{l}\text { Recurrent } \\
\text { Ameloblastoma }\end{array}$ & Primary & $18 \mathrm{~cm}$ & Subtotal & $18 \mathrm{~cm}$ & 5 segment & No \\
\hline 3 & 26 & $\mathrm{~F}$ & $\begin{array}{l}\text { Post-operative } \\
\text { deformity }\end{array}$ & Secondary & $15 \mathrm{~cm}$ & Subtotal & $15 \mathrm{~cm}$ & 5 segment & No \\
\hline
\end{tabular}

Cases

Case 1 compriseda 26 years old manwithameloblastoma on right side of the mandible. His CAT classification was CATT. The mandibular defect range was $12 \mathrm{~cm}$; the number of mandible osteotomy sites was 4 ; and the height of the mandible reconstruction was single barrel. Subtotal mandibulactomy done from left canine to right Condyle (disarticulation) on 28/5/2014. Free fibular flap from right leg (12cm fibula with FHL muscle with $\left.4 \mathrm{X} 2 \mathrm{~cm}^{2}\right)$ is harvested by 3 segment osteotomies \& shaped with reconstruction plate (20 holes without condyle) by 11 screws. Vascular anastomosis was - right peroneal artery with right facial artery; peroneal vein with right anterior jugular vein (end to end), ligature by $8-0$ prolene. Relevant pictogram are shown in figure 2 .

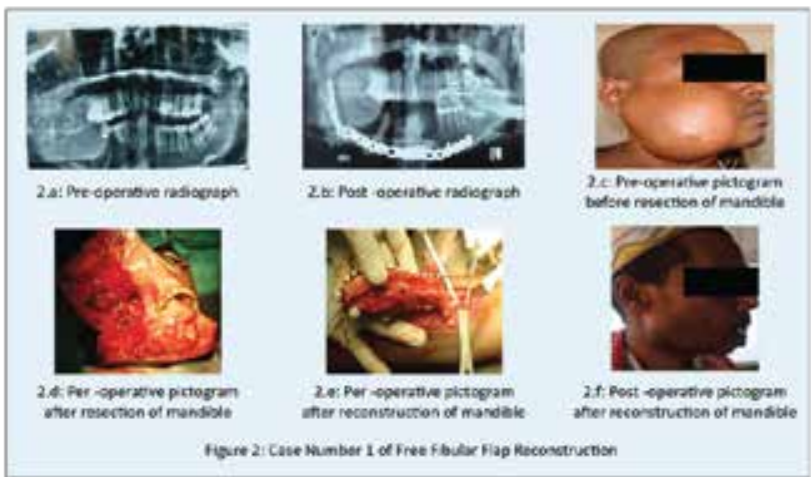

Case 2 compriseda 25 years old manwith recurrent ameloblastoma on right side of the mandible. His CAT classification was CATTAC. The mandibular defect range was $18 \mathrm{~cm}$; and the height of the mandible reconstruction was single barrel. Subtotal mandibulactomy done from left angleto right Condyle (disarticulation) on 19/8/2014. Free fibular flap from right leg (18cm fibula with FHL muscle) is harvested by 5 segment osteotomies \& shaped with reconstruction plate (without condyle) by 10 screws. Vascular anastomosis was - right peroneal artery with right facial artery; peroneal vein with right facial vein and right anterior jugular vein (end to end), ligature by 8-0 prolene.
Relevant pictogram are shown in figure 3.

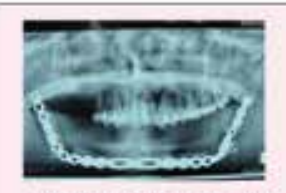

3.: Post-operntive rad ocraph

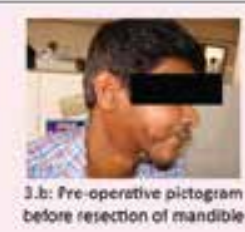

besore reicurion of mandibie

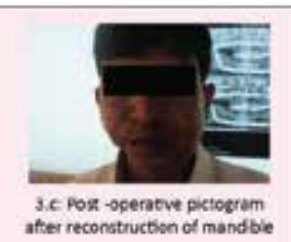

after reconatruction of mand bie
Figure-3: Case number 2 of free fibular flap reconstruction.

Case 3 compriseda 26 years old femalewith post-surgical facial deformity on left side of the mandible. His CAT classification was $\neg$ TTAC. The mandibular defect range was $15 \mathrm{~cm}$; the number of mandible osteotomy sites was 5; and the height of the mandible reconstruction was single barrel. Subtotalmandibulectomy done from right first molar to left condyl on 19/11/2014. Free fibular flap from right leg (15cm fibula with FHL muscle) is harvested by 5 segment osteotomies \& shaped with reconstruction plate (without condyle) by 15 screws. Vascular anastomosis was - right peroneal artery with right facial artery; peroneal vein with right facial vein and right anterior jugular vein (end to end), ligature by $8-0$ prolene. Relevant pictogram are shown in figure 4.

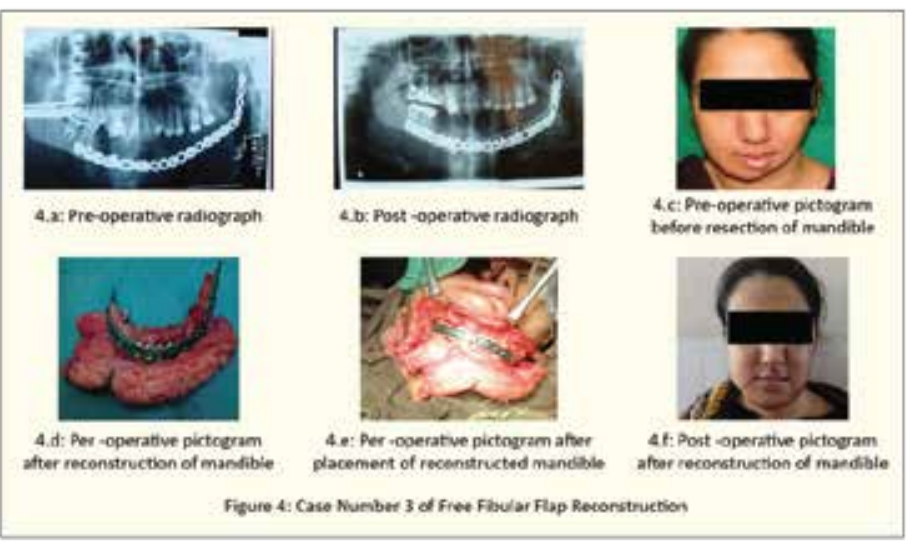

\section{Discussion}

According to Nagamatsu $\mathrm{S}$ et al. reconstruction with only a metal plate was useful as a provisional solution, but that it had long-term problems ${ }^{9}$. On the contrary, block transplant by free iliac bone also has drawbacks, for example limitations of the quantity of bone which can be harvested, and bone resorption after transplant ${ }^{4}$.

Studies have recommended that this difficult can be overcome by reconstruction the mandible by vascularized osteocortical flap in combination with microvascular surgery ${ }^{7,10}$. The fibula is exclusively fit for mandibular reconstruction in relationships of bone length, strength, multiplicity of cortical bones, adaptability to bone formation, and disture-bance of the site of harvest ${ }^{4}$. Peter G. Cordeiro recommended the fibula as the principal choice in mandibular reconstruction ${ }^{11}$.

Former studies have noted a number of other benefits with a fibular flap in this admiration. These comprise a high 
engraftment ration; on experimental bone resorption; applicability in most cases up to $20 \mathrm{~cm}$; osteotomy of bone graft, allowing 3-dimensional conformation of mandibular bone, if the alveolar area can be reconstructed by folding into two (double barrel method ); and suitability for insertion of implant ${ }^{3,7}$. No implants were worn to re-establish occlusion, here. This does not indicate that implants will be lined out in future patients. Conversely the conclusion will have to be made based on complete concern of both fibular height and soft tissue conditions. In this situationthe width of the attached gingival of soft tissue should also be measured.

Mandibular reconstruction has been reproduced using reconstruction plates for many years at Dhaka Dental College. It was found that betterprecision could be achieved if the bone to be transplanted was familiar in harmony with plaster moulded 3-dimensional models in order to confirm compatibility first. Fibular transplant requires a microsurgical angiostomy. The correlations between the number of fibular osteotomy sites, mandible resection range, primary disease, and fibular necrosis were also investigated. No association was observed among fibular necrosis and the number of fibular osteotomy sites or range of mandibular resection.

In our study primary disease comprised ameloblastoma, recurrent ameloblastoma, and post-surgical facial deformity. Body was the most commonly observed defect by the CAT classification. All mandibular bones were left as single barrel among these 2 cases were primary reconstruction and 1 of secondary reconstruction. Subtotal mandibulectomy from incisors to condyle was done in two cases. Vascular anastomosis was peroneal artery with facial artery and peroneal vein with Facial vein and Ant. jugular vein (end to end). No postoperative complications were seen in any case.

In the case of supplementary soft tissue defect, a fibula graft can be harvested with various reliable skin paddles ${ }^{12}$. which allow a one-stage reconstructive method of composite mandibular defects ${ }^{13,14}$. Numerous modifications of skin paddles have been described ${ }^{15}$. An extra benefit of the free vascularized fibula graft is the capability to have two teams working at the same time with the patient in the supine position by reducing operating time, which is related with reduced blood loss and lower rates of infection ${ }^{16}$. As well, the blood supply can be monitored postoperatively with an implantable Cook-Swartz Doppler probe ${ }^{17,18}$. The donor site morbidity of the FFF is always acceptable among different studies, and is typically avoidable with suspicious planning and appropriate technique ${ }^{19}$.

One difficulty of the free fibula flap is the height difference between the native mandible and the transplanted fibula, particularly at the anterior segment. The 'double-barreling' of the fibula is a practical modification with good aesthetic and functional outcomes ${ }^{20,21}$. The 'double-barreling' of the fibula enables instant osseointegrated dental implantation ${ }^{22}$. Preoperative virtual surgery planning using 3D technology has shown convincing improvements in postoperative outcomes $^{23}$.

According to Yamamoto et al. when a fibular transplant is performed in a patient with radiation osteomyelitis of the mandible, a number of steps will have to be taken further along. These comprise: 1) performing the surgery after improvement of infection of the mouth and neck;2) selecting appropriate postoperative antibiotics that are effective against osteomyelitis and performing drainage more strictly; and 3) displaying caution when selecting a blood vessel for anastomosis outside the exposure field.

\section{Conclusion}

The results of the current study suggest free vascularized fibular flap is good choice in wide-range faults hard to fill with an iliac block graft. Further studies including greater samples of patients undertaking fibular bone transplantation are needed to comparatively investigate its merits in more detail.

\section{Conflict of Interests: None}

\section{Acknowledgement}

In designing of manuscript we follow the pattern of clinical report of The Bulletin of Tokyo Dental College by Yamamoto $\mathrm{N}$ et.al. The faculties of oral \& maxillofacial surgery of Dhaka dental college \&hospital. The authors wish to declare no conflict of interest with regard to this paper.

\section{References}

1. Grillon GL, Gunther SF, Connole PW. A new technique for obtaining iliac bone grafts. Journal of Oral and Maxillofacial Surgery. 1984;42:172-6.

https://doi.org/10.1016/S0278-2391(84)80028-2.

PMID: 6366173

2. Sakuraba M, Kimata Y, Uchida G, Sarukawa S, Kadota $H$, Kashiwaya G, et al. Measures for preventing postoperative complications after mandibular reconstruction with free fibular flaps. Journal of Reconstructive Microsurgery. 2006;22:A081.

3. Hidalgo DA, Pusic AL, Wei FC. Free-flap mandibular reconstruction: a 10-year follow-up study. Plastic and reconstructive surgery. 2002;110:438-49.

4. Yamamoto N, Morikawa T, Yakushiji T, Shibahara T. Mandibular Reconstruction with Free Vascularized Fibular Graft. The Bulletin of Tokyo Dental College. 2018;59:299-311.

https://doi.org/10.2209/tdcpublication.2017-0025

PMid:30333367

5. Takushima A, Harii K, Asato H, Nakatsuka T, Kimata Y. Mandibular reconstruction using microvascular free flaps: a statistical analysis of 178 cases. Plastic and reconstructive surgery. 200;108:1555-63. 
https://doi.org/10.1097/00006534-200111000-00018.

PMid: 11711927

6. Taylor GI, Miller GD, Ham FJ. The free vascularized bone graft. A clinical extension of microvascular techniques. Plastic and reconstructive surgery. 1975;55:533-44.

PMid: 1096183

7. Hidalgo DA. Fibula free flap: a new method of mandible reconstruction. Plastic and reconstructive surgery. 1989;84:71-9.PMid: 2734406

8 .Hashikawa K, Tahara S, Sugiyama D, Yokoo S, Hyodo I, Motomura $\mathrm{H}$, et al. Validity and utility of CAT classification system for oncological mandibular defects a multi-institutional study. ToukeibuGan. 2010;36:309-15.

9. Nagamatsu S, Kamizono K, Sakuraba M, Miyamoto S, Kayano S, Fujiki M, et al. 'No touch technique' - Simple method to reduce postoperative complications in mandibular reconstruction using a reconstruction plate. $\mathbf{J}$ Jpn SRM. 2014;27: 48-55.

https://doi.org/10.2209/tdcpublication.2017-0025

10. Salibian AH, Rappaport I, Allison G. Functional oromandibular reconstruction with the microvascular composite groin flap. Plast Reconst Surg. 1985;76: 819-825.

PMid:3906715

11. Cordeiro PG, Disa JJ, Hidalgo DA. Reconstruction of the mandible with osseous free flap; A 10-year experience with 150 consecutive patients. Plast Reconstr Surg 1999;104: 1314-1320.

PMid:10513911

12. Erdmann D, Giessler GA, Bergquist GE. Free fibula transfer: analysis of 76 consecutive microsurgical procedures and review of the literature. Chirurg. 2004;75:799-809.

13. Minami A, Usui M, Ogino T. Simultaneous reconstruction of bone and skin defects by free fibular graft with a skin flap. Microsurgery. 1986;7:38-45. PMid:3702664

14. Van Twisk R, Pavlov PW, Sonneveld J. Reconstruction of bone and soft tissue defects with free fibula transfer. Ann Plast Surg. 1988;21:555-558.

PMid:3239933

15. Loeffelbein DJ, Holzle F, Wolff KD. Double-skin paddle perforator flap from the lateral lower leg for reconstruction of through-and-through cheek defect: a report of two cases. Int $\mathrm{J}$ Oral Maxillofac Surg. 2006;35:1016-1020.

https://doi.org/10.1016/j.ijom.2006.08.008
16. Rosenberg AJ, Van Cann EM, Van Der Bilt A. A prospective study on prognostic factors for free-flap reconstructions of head and neck defects. Int $\mathrm{J}$ Oral Maxillofac Surg. 2009;38:666-670.

https://doi.org/10.1016/j.ijom.2009.01.012

17. Guillemaud JP, Seikaly H, Cote D. The implantable Cook-Swartz Doppler probe for postoperative monitoring in head and neck free flap reconstruction. Arch Otolaryngol Head Neck Surg. 2008;134:729-734.

https://doi.org/10.1001/archotol.134.7.729.

PMid: 18645123

18. Kind GM, Buntic RF, Buncke GM. The effect of an implantable Doppler probe on the salvage of microvascular tissue transplants. Plast Reconstr Surg. 1998;101:1268-1273.

https://doi.org/10.1097/00006534-199804050-00016.

PMid: 9529212

19. Hidalgo DA, Pusic AL. Free-flap mandibular reconstruction: a 10-year follow-up study. PlastReconstr Surg. 2002;110:438-449.

URL: https://pdfs.semanticscholar.org/ad45/6e5c6fc23d80 1e26984469bac50793175d4e.pdf

20. Strackee SD, Kroon FH, Jaspers JE. Modeling a fibula transplant in mandibular reconstructions: evaluation of the effects of a minimal number of osteotomies on the contour of the jaw. PlastReconstr Surg. 2001;108:1915-1921.

https://doi.org/10.1097/00006534-200112000-00010. PMid: 11743376

21. Wallace CG, Chang YM, Tsai CY. Harnessing the potential of the free fibula osteoseptocutaneous flap in mandible reconstruction. Plast Reconstr Surg. 2010;125:305-314.

https://doi.org/10.1097/PRS.0b013e3181c2bb9d

22. Chang YM, Wallace CG, Hsu YM. Outcome of osseointegrated dental implants in double-barrel and vertically distracted fibula osteoseptocutaneous free flaps for segmental mandibular defect reconstruction. Plast Reconstr Surg. 2014;134:1033-1043. https://doi.org/10.1097/PRS.0000000000000623

23. Wang WH, Zhu J, Deng JY. Three-dimensional virtual technology in reconstruction of mandibular defect including condyle using double-barrel vascularized fibula flap. J Craniomaxillofac Surg. 2013;41:417-422.

https://doi.org/10.1016/j.jcms.2012.11.008 